\title{
Detailed Dynamic Modeling, Control, and Analysis of a Grid-Connected Variable Speed SCIG Wind Energy Conversion System
}

\author{
Samuel Wanjoeh, Ghadir Radman \\ Electrical and Computer Engineering Department, Tennessee Technological University, Cookeville, United States \\ Email address: \\ skwanjoeh42@students.tntech.edu (S. Wanjoeh), gradan@tntech.edu (G. Radman)

\section{To cite this article:} \\ Samuel Wanjoeh, Ghadir Radman. Detailed Dynamic Modeling, Control, and Analysis of a Grid-Connected Variable Speed SCIG Wind \\ Energy Conversion System. American Journal of Electrical Power and Energy Systems. Vol. 10, No. 2, 2021, pp. 15-24. \\ doi: $10.11648 /$ j.epes. 20211002.11
}

Received: February 3, 2021; Accepted: April 9, 2021; Published: April 23, 2021

\begin{abstract}
Wind energy as a renewable energy source continues to be a better alternative to fossil-fuel based generation due to its low cost and environmental benefits. While considerable research efforts have been focused on modeling and control of grid connected variable speed squirrel cage induction generator (SCIG) wind energy conversion systems (WECS), comprehensive models for grid integration studies have been almost non-existent. This paper presents the detail modeling, control and analysis of a grid-connected 2.25-MW variable speed SCIG based WECS that can be utilized for grid integration studies. The presented WECS model consists of a pitch regulated wind turbine connected to a SCIG through a gear box. Then, a full-capacity power electronic converter with maximum power point tracking (MPPT), dc bus voltage regulation and power factor correction, connects the SCIG to the grid. The power converter system comprises of back to back two-level voltage source converters linked through a dc-link capacitor. The generator and grid-side converters are controlled using indirect rotor field-oriented control (IR-FOC) and voltage-oriented control (VOC) respectively. The overall system is simulated in MATLAB/Simulink for a varying wind speed. Results show that the presented model is adequate and efficient in the representation of a variable speed SCIG WECS. In addition, the model meets all of the system performance objectives while simultaneously meeting all of the control objectives.
\end{abstract}

Keywords: Modeling, Control, Simulation, Squirrel Cage Induction Generator, AC/DC/AC Converter, WECS

\section{Introduction}

TO DATE, the global penetration of renewable energy sources into the grid is in an all-time high due to falling costs, increases in investments, and advances in enabling technologies. Out of all the renewable energy sources, wind energy has the least-cost option for new power generation capacity making it one of the fastest growing renewable energy resources. 2019 saw $60 \mathrm{GW}$ of annual global additions in installed wind capacity, which represented a $10 \%$ increase in global cumulative capacity [1]. It is expected that by 2025 , there will be $469 \mathrm{GW}$ of new wind capacity [2].

WECS convert energy stored in the wind to mechanical energy and finally to electrical energy. WECS are either fixed speed or variable speed. As the name implies, fixed speed WECS run at a fixed turbine rotor speed for different wind speeds. Fixed speed WECS use SCIG and are directly connected to the grid through their stator windings via a transformer and soft starter. The advantages of this configuration include low initial cost, reliable operation and simplicity. However, fixed speed WECS draw uncontrollable reactive power from the grid and are not always running at their maximum power point, as a result, they are less efficient. In addition, all fluctuations in the wind speed are further transmitted as fluctuations in the mechanical torque and then as fluctuations in the electrical power on to the grid [3-5]. On the other hand, variable speed WECS are connected to the grid through power electronic converter systems that enable MPPT operation at different wind speeds, dc bus voltage regulation and power factor correction. Furthermore, through the dc bus, the converter system fully decouples the generator from the grid thus allowing for a smoother grid output power. Due to 
these advantages, the variable speed WECS has become the standard configuration nowadays.

There are various types of generators used in the variable speed WECS. The most favorable for MW-level applications are Doubly fed induction generators (DFIGs), permanent magnetic synchronous generators (PMSGs), wound rotor synchronous generators (WRSGs), and SCIG. DFIG holds the highest market share to date but future projects announced by the wind turbine manufactures indicate that variable speed WECS with PMSG, WRSG, and SCIG will take over the wind energy market in the coming years. Among the variable speed induction generators, SCIG based WECS is expected to be the most important in the near future due to the following facts: 1) the high efficiency and the low cost installation and maintenance of the SCIG; and 2) the continuing reduced costs of the power electronic devices even in higher power levels, since the SCIG connection to the grid is implemented using a full scale back to back AC/DC/AC frequency converter $[6,7]$.

The major components of a grid connected WECS can be broadly classified as mechanical, electrical, and control systems [7]. In order to perform grid integration studies, a comprehensive model that incorporates all of these features is essential for an accurate representation of a grid connected WECS. Several papers [6, 8-16], in literature have proposed models of grid connected variable speed SCIG based WECS. However, these models are not sufficient enough in the detail characterization of the whole WECS. Most of these papers [8-14] focus on control schemes that utilize the converters to achieve optimum operation of the WECS. Others exclude wind turbine control [6], and converter control formulation $[15,16]$ in their analysis. Moreover, these models are not comprehensive enough for integration in a large-scale power systems simulation software package. From the above, it can be concluded that there is a need for a comprehensive model of a variable speed WECS based SCIG that can be utilized for grid integration studies. Such a solution has not been reported in the open literature to the best of the author's knowledge.

Aiming on the aforementioned, this paper presents a comprehensive non-linear model of a grid connected variable speed SCIG based WECS that can be utilized for grid integration studies. The presented WECS model consists of subsystems namely: a wind profile, aerodynamic model, drive train model, pitch control model, SCIG model, AC/DC/AC converter model, and a phase locked loop (PLL) model. Also presented is a detailed converter control methodology that utilizes IR-FOC and VOC to achieve MPPT tracking, dc bus voltage regulation and power factor correction. The design of the converter control loops is aided by an input-output linearization method that eliminates the nonlinearity and coupling of system equations therefore making the design of the proportional integral (PI) controllers more convenient and the system is more easily stabilized. The Butterworth method is applied to design the PI controller gains and the full-scale back to back voltage source converters, are modulated by the sinusoidal pulse width modulation (SPWM) scheme for gate turn on of insulated-gate bipolar transistor (IGBT) switches. Simulations executed in MATLB/Simulink, are presented in order to evaluate the model's performance and control effectiveness for different wind speed values.

The remainder of the paper is organized as follows: Section II presents detailed modeling and control of the proposed WECS, while Section III provides the model's performance simulation results. Section IV concludes the paper.

\section{SCIG Wind Generation System}

The schematic diagram of the grid connected variable speed WECS with SCIG is shown in Figure 1. An AC/DC/AC converter is used to connect the SCIG to the grid. The AC/DC converter is linked to the DC/AC converter by a dc-link capacitor. A line inductor, $L_{g}$, representing the leakage inductance of the transformer and a line resistor, $R_{g}$, are assumed between the grid-side converter and the grid. The rest of this section aims to describe the control methodology and model the different subsystems of the above mentioned WECS.

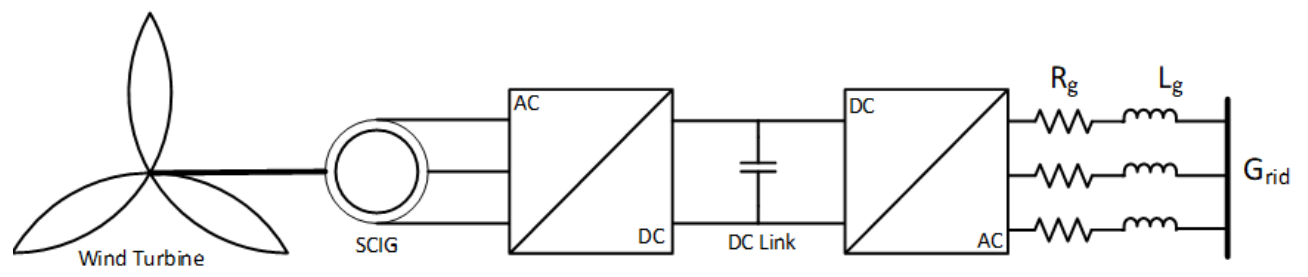

Figure 1. A simple block diagram of a variable speed WECS with SCIG.

\section{A) Wind Profile}

The wind profile is generated by an autoregressive moving average (ARMA) model [17] and is utilized in the simulation as shown in Figure 2. The wind profile, $v_{w}(t)$, is modeled as the sum of two components:

$$
v_{w}(t)=v_{m}+v_{t}(t)
$$

where $v_{m}$ is the mean wind speed at hub height and $v_{t}(t)$ is the instantaneous turbulent part and is defined by the equation:

$$
v_{t}(t)=\sigma_{t} \vartheta_{t}
$$

where $\sigma_{t}$ is the standard deviation and $\vartheta_{t}$ is the ARMA time series model:

$$
\begin{gathered}
\vartheta_{t}=\phi_{1} \vartheta_{t-1}+\phi_{1} \vartheta_{t-1} \cdots+\phi_{n} \vartheta_{t-n}+\alpha_{t}-\theta_{1} \alpha_{t-1}- \\
\theta_{2} \alpha_{t-2} \cdots-\theta_{m} \alpha_{t-m}
\end{gathered}
$$

where $\phi_{i}(i=1,2, \ldots, n)$ and $\theta_{j}(j=1,2, \ldots, m)$ are the autoregressive parameters and moving average parameters. 
Their numerical values can be found in [17].

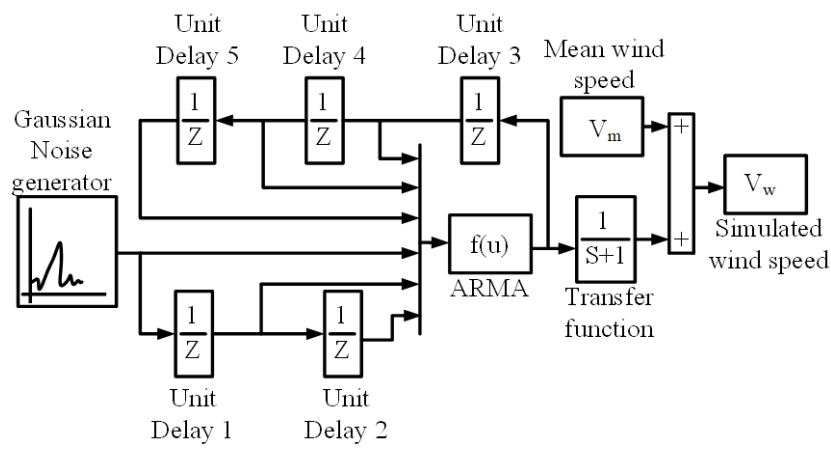

Figure 2. Generation of wind profile using ARMA model.

\section{B) Aerodynamic Model}

The wind turbine is the prime mover that converts the kinetic energy in the wind into mechanical power that produces electric power. The mechanical power is calculated as:

$$
P_{m}=\frac{1}{2} \rho A v_{w}{ }^{3} C_{p}(\lambda, \beta)
$$

where $\rho$ is the air density (in kilograms per cubic meter), $A=\pi R^{2}$ is the cross-sectional area of the wind turbine through which the wind passes (in square meter), and $R$ is the blade radius. $v_{w}$ is the wind speed (in meters per second), and $C_{p}$ is the power coefficient of the blade. The power coefficient is a function of the blade pitch angle, $\beta$ (the angle at which the rotor blades rotate on their longitudinal axis), and tip speed ratio, $\lambda$. The numerical approximation of $C_{p}$ used in this work is $[18]$ :

$$
C_{p}=0.5\left(\lambda-0.022 \beta^{2}-5.6\right) e^{-0.17 \lambda}
$$

Tip speed ratio is defined as the ratio of the blade tip speed to the wind speed:

$$
\lambda=\frac{\omega_{t} R}{v_{w}}
$$

where $\omega_{t}$, is the turbine rotor speed (in $\mathrm{rad} / \mathrm{s}$ ). The relationship between $C_{p}$ and $\lambda$ for different values of blade pitch angle ranging from zero to 26 degrees is shown in Figure 3 . From this figure, it can be inferred, that at $\beta=0$ and by choosing the optimal tip speed ratio, $\lambda_{\text {opt }}$, for the maximum power coefficient, $C_{p-\max }$, the maximum power can be extracted from the wind. Therefore, the reference mechanical speed according to the optimal tip speed ratio, $\lambda_{\text {opt }}$ is calculated by:

$$
\omega_{m}^{r e f}=\frac{\lambda_{o p t} v_{w} n_{g}}{R}
$$

where $n_{g}$ is the gearbox ratio. The reference mechanical torque is:

$$
T_{m}^{r e f}=\left.\frac{\frac{1}{2} \rho A v_{w}^{3} C_{p-\max }\left(\lambda_{o p t}, \beta\right)}{\omega_{m}^{r e f}}\right|_{\beta=0}
$$

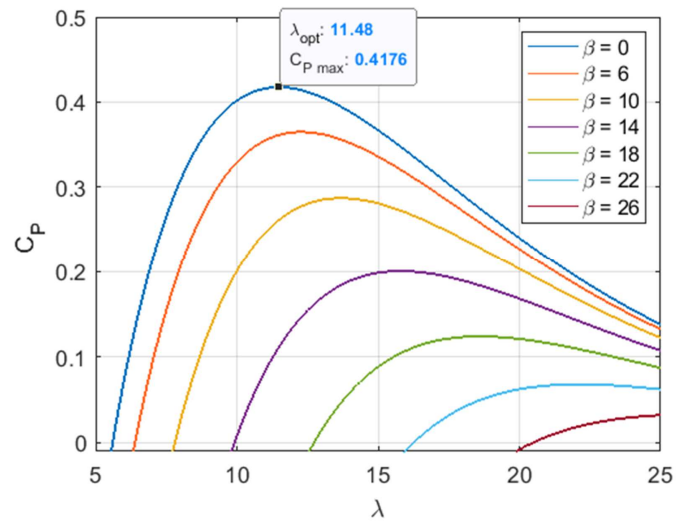

Figure 3. Power coefficient and tip speed ratio for various values of pitch angle.

\section{C) Drive Train Model}

The drive train of a WECS consists of, shafts, gearbox, and bearings. Some of the drive train components can be neglected depending upon the investigation being carried out. For example, for fixed speed WECS, a two-mass drive train model consisting of a low speed and high-speed shaft or a higher order model is required when transient stability and flicker are being investigated [19-20]. For variable speed wind WECS, the drive train dynamics have almost no effect on the grid side characteristics due to the decoupling effect of the power electronic converter system. Therefore, a one-lumped mass model consisting of a rigid low speed shaft is often considered in studies involving variable speed WECS [21]. Figure 4 shows the one-lumped model and thereafter, are the model's governing equations.

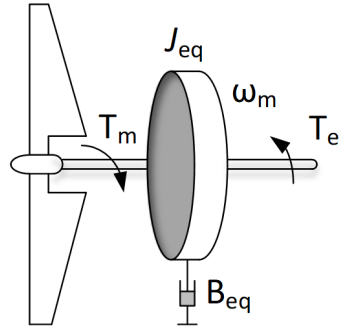

Figure 4. One mass model of the wind turbine.

$$
\begin{gathered}
J_{e q} \frac{d \omega_{m}}{d t}=\frac{T_{m}}{n_{g}}+T_{e}-B_{e q} \omega_{m} \\
n_{g}=\frac{T_{m}}{T_{m \_g}}=\frac{\omega_{m}}{w_{t}}
\end{gathered}
$$

where

$$
\begin{gathered}
J_{e q}=J_{g}+\frac{J_{t}}{n_{g}^{2}} \\
B_{e q}=B_{g}+\frac{B_{t}}{n_{g}^{2}}
\end{gathered}
$$

where $J_{e q}$ is the total equivalent rotational inertia of the system and is derived from (11) where $J_{g}$ and $J_{t}$ are the generator and turbine rotor inertias respectively. $B_{e q}$ is the total external damping coefficient, and $B_{g}$ and $B_{t}$ are the 
generator and turbine damping coefficients respectively. The electromagnetic torque is $T_{e}$ and the mechanical torque transferred to the generator side is $T_{m_{-} g}$. The mechanical angular speed is $\omega_{m}$.

\section{D)Pitch Control Model}

The pitch control model consists of two operating regions, namely the partial-load region and the full-load region. In the partial-load region, the wind speed is lower than the rated wind speed. As a result, the blade pitch angle is set at zero resulting to $C_{p-\max }$ and $\lambda_{o p t}$, hence leading to maximum energy extraction from the wind turbine. In the full-load region, the wind speed exceeds its rated value and pitch control is activated to control the generator's output power. This control is accomplished by increasing the blade pitch angle to shed some of the aerodynamic power so that the generator's output power can be maintained at its rated value.



Figure 5. Pitch angle control model.

The block diagram of the implemented pitch angle control model is shown in Figure 5. The system consists of a pitch servo which is modeled as a first-order transfer function:

$$
\dot{\beta}=\frac{1}{\tau_{\beta}} \beta_{\text {ref }}-\frac{1}{\tau_{\beta}} \beta(13)
$$

For a practical response in the pitch angle control model, the pitch servo accounts for a servo time constant $\tau_{\beta}$, and the limitation of both the pitch angle from 0 to 30 degrees and its gradient $( \pm 10$ degrees/s). The error between the measured mechanical power and rated mechanical power, $\Delta P_{m}$, is sent to a PI controller with gain scheduling which outputs a reference pitch angle $\beta_{\text {ref }}$, which is then compared to the actual pitch angle, $\beta$ and the resulting error $\Delta \beta$, is corrected by the pitch servo.

The PI controller is designed with gain scheduling to provide satisfactory control over different operating points of the WECS. To design the gains of this controller, the nonlinear wind turbine dynamics are linearized about a specific operating point $\left(w_{t, O P}, \beta_{, O P}, v_{w, O P}\right)$. From (4) and expanding as a Taylor series at the operating point and neglecting higher order terms:

$$
\begin{aligned}
P_{m} & =P_{m, O P}+\Delta P_{m} \\
P_{m}-P_{m, O P} & =A \Delta w_{t}+B \Delta \beta+C \Delta v_{w} \\
A & =\left.\frac{\partial P_{m}}{\partial w_{t}}\right|_{w_{t}=w_{t, O P}} \\
B & =\left.\frac{\partial P_{m}}{\partial \beta}\right|_{\beta=\beta, O P} \\
C & =\left.\frac{\partial P_{m}}{\partial v_{w}}\right|_{v_{w}=v_{w, O P}}
\end{aligned}
$$

where the partial derivatives are evaluated at the operating points and $\Delta w_{t}=w_{t}-w_{t, O P} \quad \Delta \beta=\beta-\beta_{O P} \quad \Delta v_{w}=$ $v_{w}-v_{w, O P}$ are small changes in $w_{t}, \beta, v_{w}$ from the specified operating point. The pitch angle perturbation can be defined as a summation of the PI controller gains multiplied by the perturbed mechanical power:

$$
\Delta \beta=K_{p p} \Delta P m+K_{i p} \int \Delta P m d t
$$

Substituting (19) into (15) and transforming to Laplace transform, a transfer function of the closed loop system is obtained.

$$
\frac{\Delta P_{m}}{\Delta V_{m}}=\frac{s C}{s-s B K_{p}-B K_{i}}
$$

The denominator of the transfer function is compared to the second order butterworth polynomial, in order to determine the PI gains. This is further discussed in section F. When the operating point of the WECS changes, the PI controller gains will need to be re-designed to maintain satisfactory response from the pitch angle control model. For instant, at the turbine operating point $V_{w}=12.5, w_{t}=3.39$, and $\beta=5.2638$ the tuned gains are $K_{p p}=0.033$ and $K_{i p}=0.169$. When this operating point changes, the PI controller gains will also change. The change in performance is caused by the variation of pitch angle due to a change in wind speed which in effect also causes a change in the pitch sensitivity $\partial P_{m} / \partial \beta$. The solution to this problem is to schedule the $K_{p p}$ and $K_{i p}$ gains as a function of pitch angle. Therefore, each PI gain is scaled by a gain scheduling constant $G K(\beta)$ to ensure suitable control loop performance is attained at all wind speeds for all pitch angle variations. The gain scheduling constant [22] is given as follows:

$$
G K(\beta)=\frac{1}{\left(1+\frac{\beta}{K K}\right)}
$$

where $K K$ is determined as the pitch angle where $\partial P_{m} / \partial \beta$ has increased by a factor of 2 [23]. $\beta$ is the output of the pitch angle control model

\section{E) Squirrel Cage Induction Generator Model}

The induction generator $q d$ equivalent circuit represented in the synchronous rotating reference frame is shown in Figure 6. Its corresponding $q d$ model equations [24] are

$$
\begin{gathered}
V_{q s}=R_{s} I_{q s}+p \lambda_{q s}+w_{e} \lambda_{d s} \\
V_{d s}=R_{s} I_{d s}+p \lambda_{d s}-w_{e} \lambda_{q s} \\
0=R_{r} I_{q r}+p \lambda_{q r}+\left(w_{e}-w_{r}\right) \lambda_{d r} \\
0=R_{r} I_{d r}+p \lambda_{d r}-\left(w_{e}-w_{r}\right) \lambda_{q r} \\
\lambda_{q s}=\left(L_{l s}+L_{m}\right) I_{q s}+L_{m} I_{q r}=L_{s} I_{q s}+L_{m} I_{q r} \\
\lambda_{d s}=\left(L_{l s}+L_{m}\right) I_{d s}+L_{m} I_{d r}=L_{s} I_{d s}+L_{m} I_{d r} \\
\lambda_{q r}=\left(L_{l r}+L_{m}\right) I_{q r}+L_{m} I_{q s}=L_{r} I_{q r}+L_{m} I_{q s} \\
\lambda_{d r}=\left(L_{l r}+L_{m}\right) I_{d r}+L_{m} I_{\mathrm{d} s}=L_{r} I_{d r}+L_{m} I_{d s}
\end{gathered}
$$




$$
T_{e}=\frac{3 P L_{m}}{2 L_{r}}\left(I_{q s} \lambda_{d r}-I_{d s} \lambda_{q r}\right)
$$

where $p=d / d t$ denotes the derivative operator. $P$ is the number of pole pairs. The q-axis and d-axis stator voltages are $V_{q s}, V_{d s}$. The q-axis and d-axis stator and rotor flux linkages are $\lambda_{q s} \lambda_{d s}$ and $\lambda_{q r} \lambda_{d r}$ respectively. The q-axis and d-axis stator and rotor currents are $I_{q s} I_{d s}$ and $I_{q r} I_{d r}$, respectively. $L_{s}$ and $L_{r}$ are the stator and rotor self-inductance. $L_{l s}$ and $L_{l r}$ are the stator and rotor leakage inductances whereas $L_{m}$ is the magnetizing inductance. The rotor electrical speed is $w_{r}$ and the rotating speed of the synchronous reference frame is $w_{e}$. Lastly, $R_{s}$ and $R_{r}$ are the stator and rotor resistances.

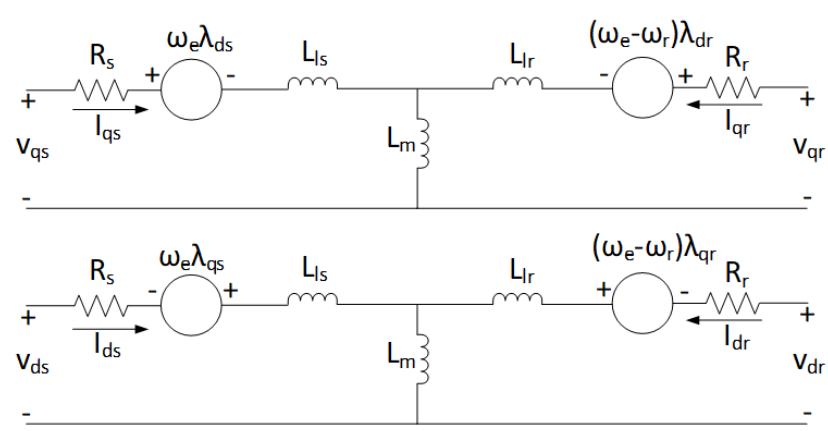

Figure 6. SCIG Equivalent circuit.

\section{F) AC/DC Converter Model}

A two-level three phase AC/DC converter is used after the induction generator. Its schematic diagram is shown in Figure 7. Writing Kirchhoff's voltage law (KVL) and Kirchhoff's current law (KCL) for the converter and transforming the equations into qd synchronous reference frame results in:

$$
\begin{gathered}
V_{q s}=\frac{1}{2} m_{q s} V_{d c} \\
V_{d s}=\frac{1}{2} m_{d s} V_{d c} \\
C p V_{d c}=\frac{3}{4}\left(m_{q s} I_{q s}+m_{d s} I_{d s}-m_{q n} I_{q g}-m_{d n} I_{d g}\right)
\end{gathered}
$$

where $I_{d g}, I_{q g}$, are the d-axis and q-axis components of the grid currents. The dc-link voltage and dc-link capacitance are $V_{d c}$ and $C$ respectively. The $\mathrm{q}$-axis and d-axis modulation components of the grid-side and generator-side converter are $m_{q n}, m_{d n}$, and $m_{q s}, m_{d s}$ respectively.

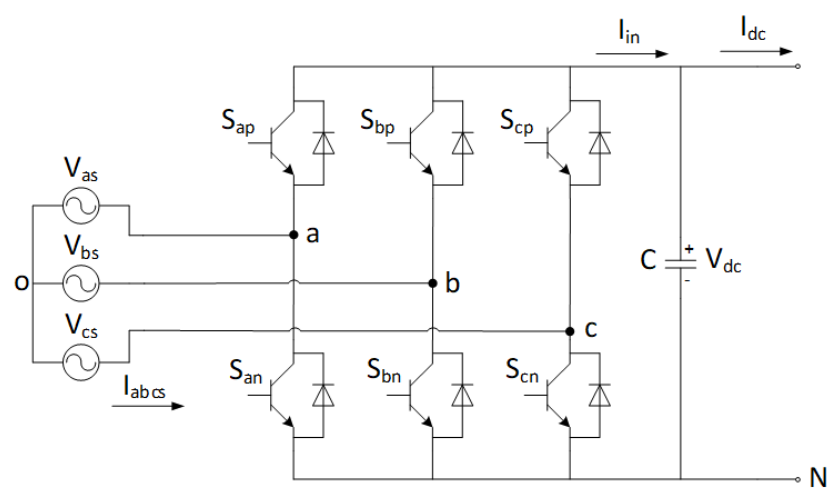

Figure 7. Generator-side converter.

\section{1) Control of $A C / D C$ Converter}

This generator-side converter is used to control the speed of the generator with an MPPT scheme. As discussed in section $\mathrm{B}$, the implemented MPPT scheme is based on maintaining the tip speed ratio at its optimum value for all wind speeds less than or equal to rated. Control is achieved by using one of the most popular control schemes used in both $\mathrm{AC}$ drives and wind energy systems namely the IR-FOC [25]. IR-FOC is achieved by aligning the $\mathrm{d}$-axis of the synchronous reference frame with the rotor flux vector while the q-axis rotor flux linkage and its derivative are zero. The resultant $q d$ axis rotor flux components are:

$$
\begin{aligned}
& \lambda_{\text {qr }}=0 \\
& \lambda_{d r}=\lambda_{r}
\end{aligned}
$$

where $\lambda_{r}$, is the magnitude of the rotor flux vector.

To apply the IR-FOC, the equations governing the induction generator, (22)-(30), are transferred to the rotor flux-model and then (34) -(35) are plugged in resulting into:

$$
\begin{gathered}
V_{q s}=R I_{q s}+L_{o} p I_{q s}+\omega_{e} L_{o} I_{d s}+\frac{L_{m} \cdot \omega_{r}}{L_{r}} \lambda_{r} \\
V_{d s}=R I_{d s}+L_{o} p I_{d s}-\omega_{e} L_{o} I_{q s}-\frac{L_{m} R_{r}}{L_{r}^{2}} \lambda_{r} \\
0=-\frac{R_{r}}{L_{r}}\left(L_{m} I_{q s}\right)+\left(\omega_{e-} \omega_{r}\right) \lambda_{r} \\
0=p \lambda_{r}+\frac{R_{r}}{L_{r}}\left(\lambda_{r}-L_{m} I_{d s}\right) \\
T_{e}=\frac{3 P L_{m}}{4 L_{r}}\left(I_{q s} \lambda_{r}\right)
\end{gathered}
$$

where

$$
\begin{gathered}
L_{o}=L_{s}-\frac{L_{m}^{2}}{L_{r}} \\
R=R_{s}+\frac{L_{m}^{2}}{L_{r}^{2}} R_{r} \\
\omega_{r}=P \omega_{m}
\end{gathered}
$$

Substituting (40) into (9) and re-arranging gives the rotor electrical speed:

$$
p \omega_{r}=\left[\frac{T_{m}}{n_{g}}+\frac{3 P L_{m}}{4 L_{r}}\left(I_{q s} \lambda_{r}\right)-\frac{B_{e q} \omega_{r}}{P}\right] \frac{P}{J_{e q}}
$$

It can be observed that (38) yields the expression of the slip frequency required for IR-FOC.

$$
\left(\omega_{e-} \omega_{r}\right)=\omega_{s l}=\frac{L_{m} I_{q s} R_{r}}{L_{r} \lambda_{r}}
$$

The stator frequency is then determined by:

$$
\omega_{e}=\omega_{r}+\omega_{s l}
$$

The angle of the rotor flux vector is obtained from (46) as:

$$
\theta_{e}=\int \omega_{e} d t
$$

It should be noted that this angle is used to transform the 
stator voltages and currents from $a b c$ variables to $q d$ synchronous reference frame. Assuming IR-FOC is implemented in steady state operating conditions, $\lambda_{r}$ is maintained at its rated value therefore the $\mathrm{d}$-axis stator reference current is calculated from (39) yielding:

$$
I_{d s, r e f}=\frac{\lambda_{r}}{L_{m}}
$$

To design the control scheme of the generator-side converter, the input-output linearization method with decoupling [26] is applied so that the non-linearity and coupling of the induction generator equations, (36)-(37) and (44) can be eliminated thus obtaining a linear relationship between the input control variables and the output-controlled variables. With this transformation, the classical linear control system theory is adopted to determine the structure of each controller as well as the constant gains of the PI controllers. The input control variables are $m_{q s}$ and $m_{d s}$ while the output-controlled variables are the rotor electrical speed $w_{r}$ and the d-axis stator current $I_{d s}$.

From (36)-(37) and (44), the current and speed controller outputs are defined as:

$$
\begin{gathered}
L_{o} p I_{q s}+R I_{q s}=k_{q s}\left(I_{q s, r e f}-I_{q s}\right) \\
L_{o} p I_{d s}+R I_{d s}=k_{d s}\left(I_{d s, r e f}-I_{d s}\right) \\
p \omega_{r}=k_{\omega r}\left(\omega_{r, r e f}-\omega_{r}\right)
\end{gathered}
$$

where $k_{q s}, k_{d s}, k_{w r}$ are the transfer functions of the PI controllers for the stator q-axis current, stator d-axis current, and speed controller respectively. They are defined as:

$$
k_{q s}=k_{p q s}+\frac{k_{i q s}}{s}, k_{d s}=k_{p d s}+\frac{k_{i d s}}{s}, k_{\omega r}=k_{p \omega r}+\frac{k_{i \omega r}}{s}
$$

Taking Laplace transform of (49)-(51) and re-arranging, the transfer functions are obtained as:

$$
\begin{gathered}
\frac{I_{q s}}{I_{q s, r e f}}=\frac{\left(s k_{p q s}+k_{i q s}\right) \frac{1}{L_{o}}}{s^{2}+\frac{s}{L_{0}}\left(R+k_{p q s}\right)+\frac{k_{i q s}}{L_{0}}} \\
\frac{I_{d s}}{I_{d s, r e f}}=\frac{\left(s k_{p d s}+k_{i d s}\right) \frac{1}{L_{O}}}{s^{2}+\frac{s}{L_{0}}\left(R+k_{p d s}\right)+\frac{k_{i d s}}{L_{0}}} \\
\frac{w_{r}}{w_{r, \text { ref }}}=\frac{s k_{p \omega r}+k_{i w r}}{s^{2}+s k_{p \omega r}+k_{i w r}}
\end{gathered}
$$

The denominator coefficients of each transfer function are then compared to a second order Butterworth polynomial to determine the PI gains of the respective controllers. The second order Butterworth polynomial is expressed as:

$$
s^{2}+2 \zeta \omega_{n} s+\omega_{n}^{2}
$$

The PI gains are selected so that the roots of the characteristic equations appear in the left half of the s-plane, on a circle of radius $\omega_{n}$, with its center at the origin. The damping coefficient, $\zeta$, is chosen for underdamped condition $(\zeta=\sqrt{2} / 2)$, while $\omega_{n}$ is chosen for a good dynamic response.

Combining (51) and (44), the q-axis stator reference current is defined as a function of the speed controller as follows:

$$
I_{q s, r e f}=\frac{\left[\frac{k_{w r}\left(\omega_{r, r e f}-\omega_{r}\right) J_{e q}}{P}-\frac{T_{m}}{n_{g}}+\frac{B_{e q} \omega_{r}}{P}\right] 4 L_{r}}{3 P L_{m} \lambda_{r}}
$$

The reference $\mathrm{q}$-axis and d-axis modulation indices used in the PWM module to generate the control signals for the IGBT are obtained by combining (36)-(37) with (49)-(50).

$$
\begin{aligned}
& m_{q s}=\frac{2}{V_{d c}}\left[k_{q s}\left(I_{q s, r e f}-I_{q s}\right)+\omega_{e} L_{o} I_{d s}+\frac{L_{m} \omega_{r}}{L_{r}} \lambda_{r}\right] \\
& m_{d s}=\frac{2}{V_{d c}}\left[k_{d s}\left(I_{d s, r e f}-I_{d s}\right)-\omega_{e} L_{o} I_{q s}-\frac{L_{m} R_{r}}{L_{r}^{2}} \lambda_{r}\right]
\end{aligned}
$$

The speed and current loops for the IR-FOC are shown in Figure 8 and Figure 9.

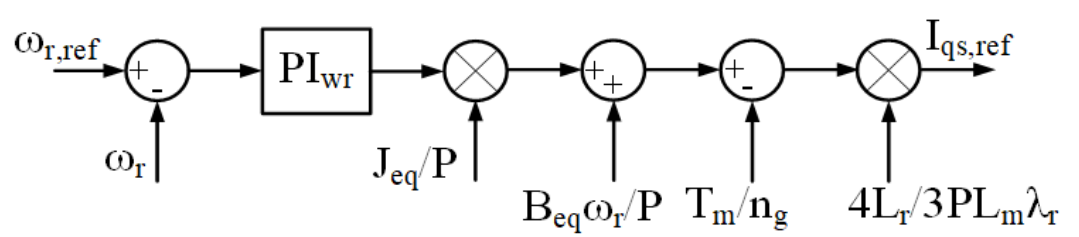

Figure 8. Rotor electrical speed control loop for the generator-side converter.

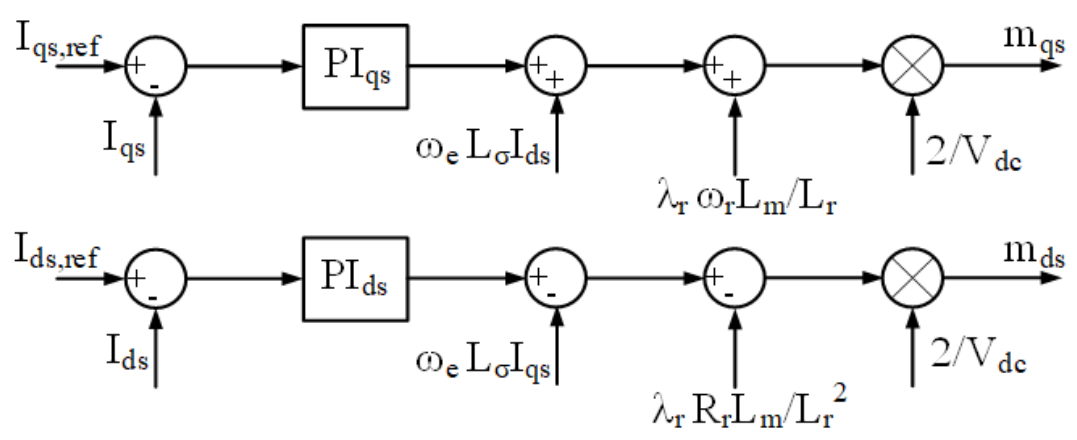

Figure 9. Current control loops for the generator-side converter. 


\section{G)DC/AC Converter Model}

A two-level three phase DC/AC converter (inverter) is shown in Figure 10. It is linked to the generator-side converter via $V_{d c}$. Using $\mathrm{KVL}$, the grid-side converter dynamic equations in $q d$ synchronous reference frame are obtained as:

$$
\begin{gathered}
V_{q n}=L_{g} \omega_{g} I_{d g}+L_{g} p I_{q g}+R_{g} I_{q g}+V_{q g} \\
V_{d n}=-L_{g} \omega_{g} I_{q g}+L_{g} p I_{d g}+R_{g} I_{d g}+V_{d g} \\
V_{q n}=\frac{1}{2} m_{q n} V_{d c} \\
V_{d n}=\frac{1}{2} m_{d n} V_{d c}
\end{gathered}
$$

where $V_{q g}, V_{d g}$ are the q-axis and d-axis components of the grid voltages; $\omega_{g}$ is the grid frequency. $V_{q n}, V_{d n}$ are the q-axis and d-axis components of the output voltage of the DC/AC converter.

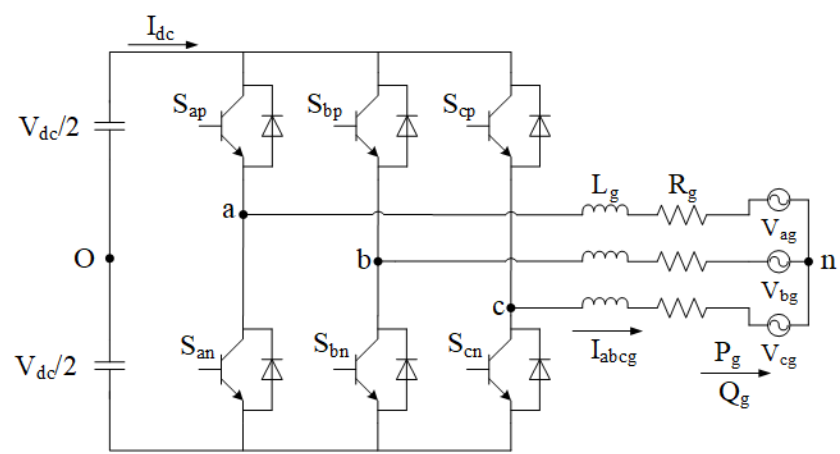

Figure 10. Grid-side converter.

\section{1) Control of $\mathrm{DC} / \mathrm{AC}$ Converter}

The objective of the grid-side converter is to keep the dc-link voltage constant and to regulate the power factor at the point of common coupling (PCC) to the grid. Control is achieved by applying VOC [25] scheme. To realize VOC, the q-axis component of the synchronous reference frame, $V_{q g}$, is aligned with the magnitude of the grid voltage, $\left(V_{q g}=\left|V_{g}\right|\right)$ while the d-axis component of the synchronous reference frame, $V_{d g}$ is regulated to zero $\left(V_{d g}=0\right)$. Therefore, the active power and reactive power injected to the grid are obtained by:

$$
\begin{gathered}
P_{g}=\frac{3}{2}\left(V_{q g} I_{q g}+V_{d g} I_{d g}\right)=\frac{3}{2}\left|V_{g}\right| I_{q g} \\
Q_{g}=\frac{3}{2}\left(V_{q g} I_{d g}-V_{d g} I_{q g}\right)=\frac{3}{2}\left|V_{g}\right| I_{d g}
\end{gathered}
$$

The power factor is regulated by controlling the d-axis grid current. From (65), the d-axis grid reference current $I_{d g \text {,ref }}$ is obtained as:

$$
I_{d g, r e f}=\frac{Q_{g}}{1.5\left|V_{g}\right|}
$$

where $Q_{g}$ can be set to zero for unity power factor operation or negative/positive value for a leading/lagging power factor.
To maintain the dc-link voltage, (33) is used to form the control loop. Multiplying both sides of (33) by $V_{d c}$ and substituting for $m_{q n}$ and $m_{d n}$ using (60) - (63) and by assuming steady state operation, yields:

$$
\frac{c}{2} p V_{d c}{ }^{2}=\left(P_{\text {in }}-P_{\text {Loss }}-\frac{3}{2} V_{q g} I_{q g}\right)
$$

where

$$
\begin{gathered}
P_{\text {in }}=\frac{3 V_{d c}}{4}\left[m_{q s} I_{q s}+m_{d s} I_{d s}\right] \\
P_{\text {Loss }}=\frac{3}{2} R_{g}\left[I_{q g}{ }^{2}+{I_{d g}}^{2}\right]
\end{gathered}
$$

The dc-link voltage loop is shown in Figure 11. The reference dc-link voltage is chosen such that the maximum magnitude of the modulating index, $M_{i}$ is 1 . The modulating index is defined as the ratio of the fundamental component amplitude of the line-to-neutral inverter output voltage to one half of the dc-link voltage.

$$
M_{i}=\frac{2 V_{m}}{V_{d c}}
$$

where $M_{i}$ is the magnitude of the modulation signal, $V_{m}$ is the magnitude of the fundamental inverter output phase voltage. From (70) the reference dc-link voltage is derived by:

$$
V_{d c, r e f} \geq 2\left(V_{m}\right)
$$

The maximum rms value of the phase voltage at SCIG terminals as well as the rms value of the inverter output phase voltage is $398.4 \mathrm{~V}$. Substituting this value in (71), $V_{d c, r e f}$ should be equal or greater than $1126.8 \mathrm{~V}$. Based on this assessment, the reference voltage of the dc-link is chosen as $1200 \mathrm{~V}$.

Using the input-output scheme discussed in section $\mathrm{F}$, the q-axis grid reference current, $I_{q g, r e f}$ and reference grid modulation indices, $m_{q n}, m_{d n}$ are obtained as follows:

$$
\begin{array}{r}
I_{q g, r e f}=\frac{2}{3 V_{q g}}\left(P_{i n}-\left[k_{d c}\left(V_{d c, r e f}{ }^{2}-V_{d c}{ }^{2}\right)\right]-P_{\text {Loss }}\right) \\
m_{q n}=\frac{2}{V_{d c}}\left[L_{g} \omega_{g} I_{d g}+k_{q g}\left(I_{q g, r e f}-I_{q g}\right)+V_{q g}\right] \\
m_{d n}=\frac{2}{V_{d c}}\left[-L_{g} \omega_{g} I_{q g}+k_{d g}\left(I_{d g, r e f}-I_{d g}\right)+V_{d g}\right]
\end{array}
$$

The current loops for the VOC are shown in Figure 12. The PI gains of the dc-link loop and current loops are determined by the method described in section $\mathrm{F}$.

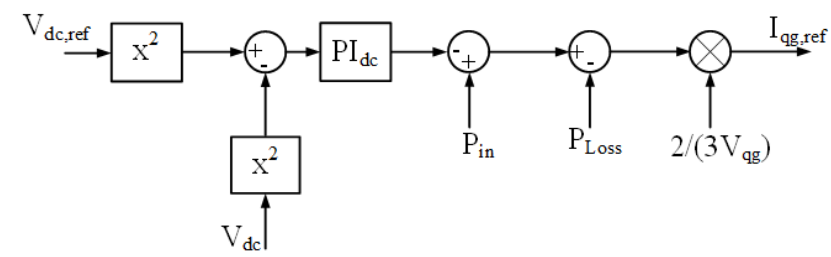

Figure 11. Dc-link voltage control loop. 


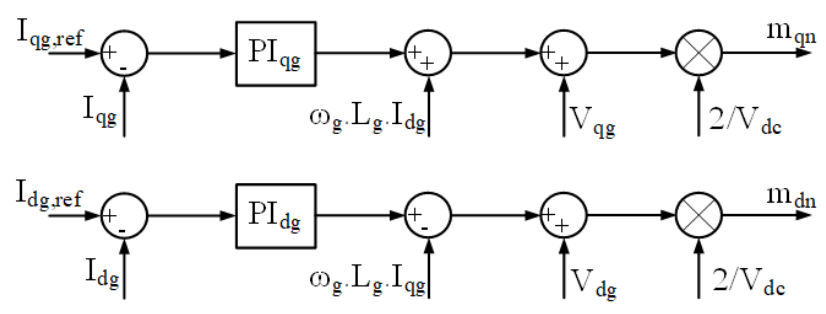

Figure 12. Current control loops for grid-side converter.

\section{2) Sinusoidal Pulse Width Modulation}

A continuous carrier based SPWM scheme is used to generate the switching functions, $S_{i p}, S_{i n}, i=a, b, c$ for the two-level converters. The reference modulation signals, $m_{q s}$, $m_{d s}, m_{q n}$ and $m_{d n}$ are transformed to $a b c$ domain as $m_{a p}$, $m_{b p}, m_{c p}, m_{a n}, m_{b n}, m_{c n}$ and are then compared to a high frequency symmetric triangular carrier signal. When the modulation signal is greater than the triangular signal, then the respective switch turns on while its complimentary switch turns off and vice versa. This relation for a respective converter leg is represented by

$$
S_{i p}+S_{\text {in }}=1
$$

\section{H)Phase Locked Loop}

A PLL [27] as shown in Figure 13 is implemented to detect the grid's voltage angle, $\theta_{g}$. This angle is used for the transformation of grid voltages and currents from the $a b c$ variables to $q d$ synchronous reference frame. The process of detecting the grid's voltage angle is realized by setting the d-axis reference grid voltage to zero $\left(V_{d g, r e f}=0\right)$, and comparing it to the transformed d-axis grid voltage, $V_{d g}$ which results in the lock in of the PLL output, $\theta$ to the grid's voltage angle $\theta_{g}$.

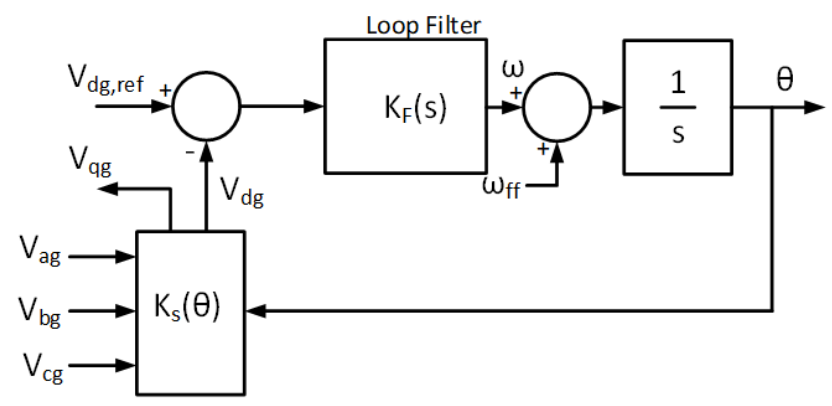

Figure 13. A PLL block diagram.

A proper design of the loop filter, $K_{F}=K_{p f}+\frac{K_{i f}}{s}$ is needed to ensure the lock in of the PLL's output to the grid's voltage angle. To tune the filter's gains, a linear PLL model is first derived. This is accomplished by first transforming the grid phase voltages, $V_{a g}, V_{b g}, V_{c g}$, to $q d$ synchronous reference frame:

$$
\begin{aligned}
& V_{q g}=V m \cos \left(\theta_{g}-\theta\right) \\
& V_{d g}=-V m \sin \left(\theta_{g}-\theta\right)
\end{aligned}
$$

Assuming the difference between the grid's voltage angle and the PLL's output, is very small, then from (77), $\sin \left(\theta_{g}-\right.$ $\theta) \approx\left(\theta_{g}-\theta\right)$ and (77) is now linearized and so is the PLL. $\mathrm{Vm}$ now appears as a gain in the forward path and the error is now defined as:

$$
e=\theta_{g}-\theta
$$

The transfer function of the closed loop is found as:

$$
\frac{\theta}{\theta_{g}}=\frac{V_{m} K_{p} s+V_{m} K_{i}}{s^{2}+V_{m} K_{p} s+V_{m} K_{i}}
$$

The PI gains are determined by the method described in section F.

\section{Simulation Results}

The proposed 2.25-MW variable speed SCIG based WECS model is implemented using MATLAB/Simulink. The WECS system is assumed to be connected to an infinite bus through its PCC bus. The infinite bus has a known voltage magnitude and angle, and represents a large power system.

The model's performance under a varying wind speed is evaluated. The rated wind speed for this study is $12 \mathrm{~m} / \mathrm{s}$. The reference rotor electrical speed for the generator-side converter controller is calculated from (7) and (43) according to the wind speed, whereas the d-axis stator reference current is set at $I_{d s, r e f}=600 \mathrm{~A}$ based on (48). For the grid-side converter controller, the reference d-axis grid current is set at $I_{d g \text {,ref }}=0$.

Figure 14(a) shows the wind speed profile generated by the ARMA model. It is shown from the simulation results, that when the wind speed is below rated speed, pitch angle, Figure 14(c), is not activated and is kept at zero. Meanwhile tip speed ratio $\lambda$, Figure $14(\mathrm{~b})$, and the power coefficient, $C_{p}$, Figure $14(\mathrm{~d})$, operate at their optimum values of 11.482 and 0.4176 in order to extract the maximum energy from the wind, i.e. MPPT operation. At above rated wind speeds, pitch angle, Figure 14(c), is activated and increases (the blades are pitched) until the excess extracted wind power is shed therefore limiting the generator's output power, Figure 14(1), to its rated value of $2.25 \mathrm{MW}$. Also, from Figure 14(1), one can see overshoots, for example at time $=7$ and time $=27$. This is due to the pitch response not being instantaneous and also due to the small dynamic variations in generator rotor speed which is allowed in order to absorb the fast wind gusts which results in the storage of rotational energy in the turbines inertial. It can also be noted, that in this control region, the wind turbine operates at a lower efficiency as seen in the decrease in performance of $C_{p}$ and $\lambda$ (are shifted downward).

Also, from the simulation results, it can be observed that the grid-side and generator-side modulation components, Figure 14(e) and Figure 14(f) operate in the linear modulation region as expected. The $q d$ stator and grid currents are shown in Figure 14(g) and Figure 14(h) respectively. It can be seen that $I_{d s}$ and $I_{d g}$ are regulated to their reference values, whereas, $I_{q s}$ and $I_{q g}$ operate at their suitable steady state values. The dc-link voltage, Figure 14(i), is maintained at its reference value by the grid-side converter while the generator-side converter regulates the generator's electrical rotor speed, Figure 14(j), to its reference value, hence, achieving MPPT. 
The reactive power is shown in Figure 14(k), and is set at zero for unity power factor operation as per (66).

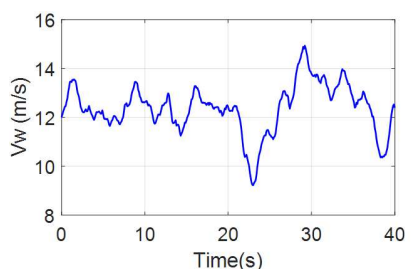

(a)

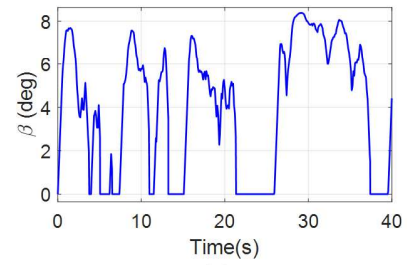

(c)

(e)

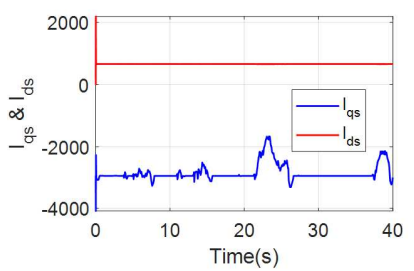

(g)

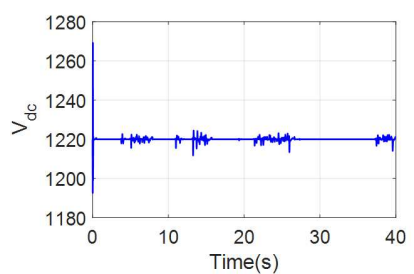

(i)

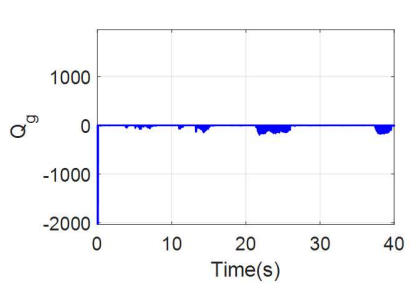

(k)

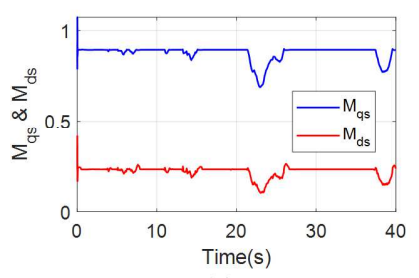

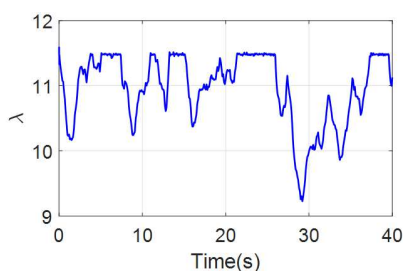

(b)

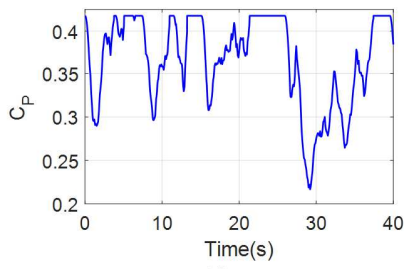

(d)

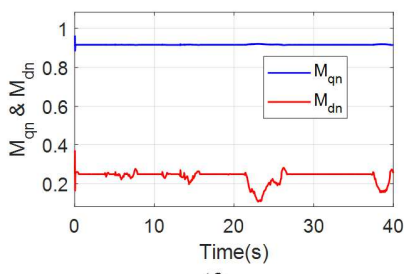

(f)

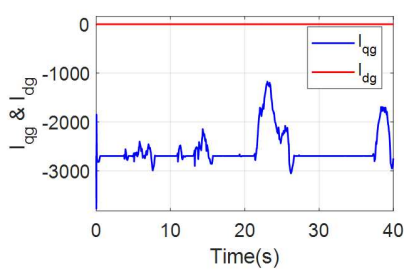

(h)



(j)

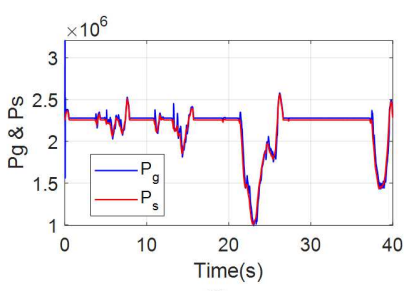

(1)
Figure 14. Simulation results of the variable speed SCIG based WECS. (a) wind speed, (b) tip speed ratio, (c) pitch angle, (d), power coefficient, (e) generator-side modulation index, (f) grid-side modulation index, (g) stator $q$-axis and d-axis currents, (h) grid q-axis and d-axis currents, (i) dc-link voltage, (j) rotor electrical speed, (k) reactive power delivered to the grid, (l) generator stator power and real power delivered to the grid.

\section{Conclusion}

This paper presented a comprehensive dynamic model of a grid connected variable speed SCIG based WECS that can be used for grid integration studies. In the WECS model, wind profile, aerodynamics, drive train, pitch control, SCIG, rectifier, inverter, and PLL have been considered. A detailed step-by-step control strategy was developed and implemented through the converter system. From simulation results, it has been shown that the presented control strategy is efficient for tracking MPPT, maintaining dc-link voltage and regulating the power factor. Also, simulation results for a fluctuating wind verify the fast and very good performance of the variable pitch control model. The developed WECS is detailed enough to capture all system performance objectives, thus, making the model suitable for inclusion in a multi-machine power system. Future work will focus on applying the model to a larger test system and investigating its performance in the presence of major disturbances such as three-phase faults, sudden load changes and line switching operation. In addition, an energy storage device with its associated controllers, will be added to the model, to smooth out the power delivered to the grid.

\section{Appendix}

\section{Table 1. WECS Data.}

\begin{tabular}{ll}
\hline$P=2$ & $\omega_{e}=377 \mathrm{rad} / \mathrm{s}$ \\
$L_{m}=2.13461 \mathrm{mH}$ & $R_{s}=1.102 \mathrm{~m} \Omega$ \\
$L_{l r}=0.06492 \mathrm{mH}$ & $R_{r}=1.497 \mathrm{mH}$ \\
$L_{l s}=0.06492 \mathrm{mH}$ & $\lambda_{r}=0.9983 \mathrm{~Wb}(\mathrm{rms})$ \\
$\rho=1.222 \mathrm{~kg} / \mathrm{m}^{3}$ & $B_{e q}=0.00015 \mathrm{~N} . \mathrm{m} . \mathrm{s} / \mathrm{rad}$ \\
$J_{e q}=18.7 \mathrm{~kg} . \mathrm{m}^{2}$ & $C=60 \mathrm{mF}$ \\
$R=40.5987 \mathrm{~m}$ & $n_{g}=55.9835$ \\
$R_{g}=0.002 \mathrm{~m} \Omega$ & $L_{g}=0.15 \mathrm{mH}$
\end{tabular}

Table 2. Controller Data for all control loops.

\begin{tabular}{lll}
\hline$K_{\text {pwr }}=5.8926$ & $K_{\text {iwr }}=17.3611$ & $K_{\text {pv }}=0.0412$ \\
$K_{\text {pqs }}=0.0290$ & $K_{\text {iqs }}=3.8730$ & $K_{i p}=0.2060$ \\
$K_{\text {pds }}=0.0290$ & $K_{\text {ids }}=3.8730$ & $K_{\text {pf }}=0.9463$ \\
$K_{\text {pdc }}=6.0670$ & $K_{\text {idc }}=613.47$ & $K_{i f}=252.2481$ \\
$K_{\text {pq. }}=0.3013$ & $K_{\text {iq. }}=306.735$ & $\tau_{\beta}=0.2$ \\
$K_{\text {pda }}=0.3013$ & $K_{\text {ida }}=306.735$ & \\
\hline
\end{tabular}

\section{References}

[1] REN21, "Renewables 2020-Global Status Report, "Renewable Energy Policy Network for the $21^{\text {st }}$ Century, 2020.

[2] GWEC, “Global Wind Report 2021, 2021.

[3] P. W. Carlin, A. S. Laxson and E. B. Muljadi, "The History and State of the Art of Variable-Speed wind Turbine Technology," Wind Energy, vol. 6, no. 2, pp. 129-159, Feb. 2003.

[4] S. S. Murthy, B. Sing, P. K. Goel and S. K. Tiwari, "A Comparative Study of Fixed Speed and Variable Speed Wind Energy Conversion Systems Feeding the Grid," in Proc. IEEE 7th Int. Conf. Power Electronics and Drive Systems Bangkok, Thailand, Nov 27-30, 2007, pp. 736-743. 
[5] T. Ackermann, Wind power in power systems. West Sussex, England: John Wiley \& Sons Ltd., 2005.

[6] G. C. Konstantopoulos and A. T. Alexandridis, "Full-Scale Modeling, Control and Analysis of Grid-Connected Wind Turbine Induction Generators with Back-to-Back AC/DC/AC Converters," IEEE Journal of Emerging and Selected Topics in Power Electronics, vol. 2, no. 4, pp. 739-748, December. 2014.

[7] V. Yaramasu, B. Wu, P. C. Sen, S. Kouro, M. Narimani, "High-Power Wind Energy Conversion Systems: State-of-the-Art and Emerging Technologies," in Proc. IEEE, vol. 103, no. 5, pp. 740-788, May 2015.

[8] A. Mesemanolis, C. Mademlis, and I. Kioskeridis, "Optimal Efficiency Control Strategy in Wind Energy Conversion System with Induction Generator," IEEE Journal of Emerging and Selected Topics in Power Electronics, vol. 1, no. 4, pp. 238-246, December. 2013.

[9] V. D. Dhareppagol and S. Nagendraprasad, "Modelling and Simulation of WECS for Maximum Power Extraction and Optimal Efficiency Control using Squirrel Cage Induction Generator," in Proc. IEEE Power, Communication and Information Technology Conference, Bhubaneswar, India, October 15-17, 2015.

[10] M. Karrari, W. Rosehart, and O. P. Malik, "Comprehensive Control Strategy for a Variable Speed Cage Machine Wind Generation Unit," IEEE Transaction on Energy Conversion, vol. 20, no. 2, pp. 415-423, June. 2005.

[11] R. Pena, R. Cardenas, R. Blasco, G. Asher and J. Clare, "A cage induction generator using back to back PWM converters for variable speed grid connected wind energy system," in Proc. IEEE Industrial Electronics Society, Denver, CO, USA, 29 Nov-2 Dec, 2001, pp. 1376-1381.

[12] Manaullah, A. K. Sharma, H. Ahuja, G. Bhuvaneswari, R. Balasubramanian, "Control and Dynamic Analysis of Grid Connected Variable Speed SCIG Based Wind Energy Conversion System," in Proc. IEEE 4th Int. Conf. Computational Intelligence and Communication Networks, Mathura, India, Nov 3-5, 2012, pp. 588-593.

[13] B. Kedjar and K. Al-Haddad, "Optimal control of a grid connected variable speed wind energy conversion system based on squirrel cage induction generator," in Proc. IEEE Industrial Electronics Society Montreal, QC, Canada, Oct 25-28, 2012, pp. 3560-3565.

[14] M. G. Simoes, B. K. Bose and R. J. Spiegel, "Design and performance evaluation of a fuzzy-logic-based variable-speed wind generation system," IEEE Transactions on Industry Applications, vol. 33, no. 4, pp. 956-965, July-August. 1997.

[15] M. K. Paul, M. L. Doumbia and A. Chériti, "Modeling and control of induction generator applied to variable speed Wind Energy Systems Conversion," in Proc. IEEE Electrical Power and Energy Conference, London, ON, Canada, Oct 26-28, 2015, pp. 314-319.

[16] B. Bechir, B. Faouzi, and M. Gasmi, "Wind energy conversion system with full-scale power converter and squirrel cage induction generator," Int. J. Physical Sciences, vol. 7, no. 46, pp. 6093-6104, Dec. 2012.

[17] Endusa Billy Muhando et al., "LQG Design for Megawatt-Class WECS With DFIG Based on Functional
Models' Fidelity Prerequisites," IEEE Transaction on Energy Conversion, vol. 24, no. 4, pp. 893-904, Dec. 2009.

[18] P. M. Anderson and Anjan Bose, "Stability Simulation of Wind Turbine Systems," IEEE Transaction on Power Apparatus and Systems, vol. 102, no. 12, pp. 3791-3795, Dec. 1983.

[19] V. Akhmatova, H. Knudsena, and A. H. Nielsenb, "Advanced simulation of windmills in the electric power supply," Int. J. Elect. Power Energy Sys., vol. 22, no. 6, pp. 421-434, Aug. 2004.

[20] S. M. Muyeen, T. Murata, and J. Tamura, Stability Augmentation of a Grid-Connected Wind Farm. London, UK: Springer-Verlag, 2008.

[21] J. G. Slootweg, S. W. H. de Haan, H. Polinder, and W. L. Kling, "General Model for Representing Variable Speed Wind Turbines in Power System Dynamics Simulations," IEEE Transaction on Power Systems, vol. 18, no. 1, pp. 144-151, Feb. 2003.

[22] A. D Wright and L. J. Fingersh, "Advanced Control Design for Wind Turbines," National Renewable Energy Laboratory, Golden, CO, USA, NREL Rep. TP-500-42437, March. 2008.

[23] M. H. Hansen et al, "Control design for a pitch-regulated variable speed wind turbine," Rise National Laboratory, Roskilde, Denmark, RISO Rep. R-1500, January. 2005.

[24] P. C. Krause, Oleg Wasynczuk and Scott D. Sudhoff, Analysis of Electric Machinery and Drive Systems. NY, USA: John Wiley \& Sons Inc., 2002.

[25] B. Wu, Y. Lang, N. Zargari and S. Kouro, Power Conversion and Control of Wind Energy Systems. NJ, USA: John Wiley \& Sons, 2011.

[26] Z. Wu, "An investigation of dual stator winding induction machines," Doctoral dissertation, Tennessee Tech University, Cookeville, TN, USA, December. 206.

[27] F. Blaabjerg, R. Teodorescu, M. Liserre and A. V. Timbus, "Overview of Control and Grid Synchronization for Distributed Power Generation Systems," IEEE Transaction on Industrial Electronics, vol. 53, no. 5, pp. 1398-1409, October. 2006.

\section{Biography}

Samuel Wanjoeh is currently working toward the Ph.D. degree in electrical engineering at Tennessee Technological University, Cookeville, TN, USA. His current research interests include power systems, integration of renewable energy sources, storage units, dynamics of power systems, and mathematical modeling of power systems.

Ghadir Radman received his Ph.D. degree in electrical engineering from Tennessee Technological University, Cookeville, TN, USA. He is currently a Professor of electrical engineering at Tennessee Technological University. His research interests include power system dynamics, power flow control, FACTS, distributed generation, smart grid and large-scale systems. Dr. Radman is a senior member of the IEEE Power \& Energy Society. 